\title{
Una Perspectiva Situada de la Investigación Cualitativa en Ciencias Sociales
}

\author{
A SITUATED APPROACH OF THE QUALITATIVE RESEARCH IN SOCIAL SCIENCE \\ Dr. Juan Sandoval (juan.sandoval@uv.cl) Escuela de Psicología, Universidad de Valparaíso (Valparaíso, Chile)
}

\begin{abstract}
In the present essay we propose explore a situated approach to knowledge, the action and the discourse; analysing some of its theoretical and epistemological implications for the qualitative research in social science. First, based on notions of background and articulation, we propose one theoretical scheme about knowledge as "situated action". Secondly, we analyse the implications of this theoretical approach, in the conceptual perspective of discourse, and then in the methodological field, on the ways of implementing the qualitative social research practices.
\end{abstract}

Key words: background, articulation, discourse, epistemology, qualitative research

\section{Resumen}

En el presente ensayo nos proponemos explorar una perspectiva situada del conocimiento, la acción y el discurso, analizando algunas de sus principales implicancias teóricas y epistemológicas para la investigación cualitativa en ciencias sociales. En primer lugar, pretendemos desarrollar un esquema teórico sobre el conocimiento como "acción situada" a partir de nociones como trasfondo y articulación. En segundo lugar, nos proponemos analizar las implicancias de esta perspectiva teórica, en el plano conceptual sobre la noción de discurso, y en el plano metodológico sobre las formas de implementar las prácticas cualitativas de investigación social.

Palabras clave: trasfondo, articulación, discurso, epistemología, investigación cualitativa

\section{Presentación}

En los últimos veinte años se han venido desarrollando en las distintas disciplinas de las ciencias sociales un conjunto de enfoques y perspectivas sobre el conocimiento y la acción, los que por medio de trayectorias diferentes, se han propuesto formular perspectivas críticas ante los grandes movimientos objetivistas y subjetivistas que hegemonizaron el desarrollo de la investigación social de gran parte del siglo XX.

En efecto, después de la transformación epistemológica que representó el giro construccionista de las ciencias sociales, que trajo como una de sus consecuencia principales la crítica a la dicotomía sujeto-objeto como fundamento del conocimiento objetivo, han surgido múltiples perspectivas que se han propuesto tomar distancia de las paradojas que representa el objetivismo y el relativismo ingenuo, entre las cuales podemos destacar el enfoque de los "conocimientos situados" (Harawey 1995). Desde esta perspectiva, el conocimiento es parcial y "posicionado" ya que surge de las características semiótico-materiales de las posiciones y articulaciones a partir de las cuales conocemos y que estarían en constante transformación. Es decir, no existiría la posibilidad de conocer desde ninguna parte, siempre lo haríamos desde un cuerpo, un tiempo y un lugar.

El conocimiento situado, al estar posicionado, tiene diferentes significados según el contexto en el cual se articula, 
de modo que su teorización, más que ubicarse en la confrontación estéril entre una suerte de universalismo racionalista y un particularismo relativista, se propone argumentar una mirada del conocimiento como "contextualmente situado", es decir, una visión epistemológica desde la cual todas las formas de conocer de nuestra vida social están situadas en un contexto histórico y corporal.

Desde esta perspectiva, el problema fundamental de la investigación en ciencias sociales sería comprender que el conocimiento constituye una forma de práctica social que no surge en el vacío y que debe ser analizado en un contexto que adquiere sentido desde un cúmulo de relaciones sedimentadas en un trasfondo de naturaleza semiótico-material. A partir de lo anterior, proponemos entender el conocimiento como una "acción situada", es decir, como el producto de un trasfondo corporal e histórico en el cual se articulan saberes y prácticas, con artefactos, espacios y tradiciones que hacen parte de una forma de vida.

En el presente ensayo nos proponemos desarrollar esta perspectiva, abordando en primer lugar, nuestra propuesta sobre el conocimiento como una acción situada en un marco de producción y reproducción históricocorporal; para analizar posteriormente, desde este esquema teórico- epistemológico la noción de discurso; para finalmente explorar algunas de las consecuencias de esta perspectiva sobre el conocimiento en las prácticas de investigación cualitativas en ciencias sociales.

\section{La perspectiva del conocimiento como acción situada: trasfondo y articulación}

Para la perspectiva del conocimiento como acción situada, el objetivo de la investigación social es comprender que las prácticas sociales deben ser analizadas a partir de un contexto de naturaleza semiótico-material que denominamos trasfondo (Sandoval 2004). En términos esquemáticos, podemos señalar que la tesis de nuestra argumentación es doble: primero, que la investigación de los procesos humanos de significación y construcción del mundo social deben ser considerados como acciones situadas en un trasfondo de naturaleza semiótico-material sedimentado como corporalidad y forma de vida; y segundo, directamente relacionado con lo anterior, que el proceso de construcción de la realidad no corresponde a una acción unilateralmente humana, sino que más bien responde a un proceso de articulación e hibridación entre agencias de naturaleza material y simbólica.

\section{a. El trasfondo de la acción: cuerpo y forma de vida}

La idea de "trasfondo" se refiere originalmente a un concepto propuesto por Searle (1992) para dar cuenta del contexto que posibilita la acción intencional del sujeto. Según este autor, los estados intencionales refieren a una particular propiedad de los estados mentales humanos en virtud de la cual éstos se dirigen a, o son sobre algún objeto o estado del mundo, es decir, la intencionalidad refiere a esa cualidad fundamental a partir de la cual la acción siempre debe ser sobre algo.

Sin embargo, la senda conceptual abierta por Searle, no satisface el objetivo de situar al conocimiento en un marco posibilitante de naturaleza semiótico-material. Para ello, debemos trascender el ámbito de la intencionalidad y entender que el concepto de trasfondo refiere a una cualidad de la acción significante, conformando al mismo tiempo su condición de posibilidad subjetiva y cultural. Esto hace necesario hacer converger las tesis de Searle con otras tradiciones conceptuales de raíz sociológica, de modo que, desde esta hibridación teórica se pueda afirmar que el trasfondo es la articulación contingente de capacidades, disposiciones corporales, saberes y reglas de una forma de vida.

Desde esta perspectiva, podemos entender que la acción de conocer, al constituir un momento en una corriente más general denominada práctica social, estaría situada en unas regularidades constituyentes de un "marco" que la posibilita como una acción puntual (re)producida material y simbólicamente por esas prácticas. En el marco de esta perspectiva, el concepto de "trasfondo" lo entendemos aquí como un contexto de constricciones que actúan como condición de posibilidad de los procesos de dotación de sentido: "el trasfondo podría corresponder a un contexto de tradiciones, relaciones de poder, capacidades, creencias, saberes y prácticas, que con una realidad primariamente biológica y necesariamente social, posibilitaría el acontecer discursivo al acotar un ámbito de 
conocimientos y prácticas donde la forma de vida Wittgensteiniana se hace cuerpo y subjetividad" (Sandoval 2004:140).

Desde esta perspectiva, la noción dualista del conocimiento se vería superada por una noción que aquí entendemos como acción situada en un trasfondo, y que para algunos autores sería compatible con las proposiciones epistemológicas antirepresentacionistas del construccionismo social. Para analizar esta noción de trasfondo, podemos poner en confluencia dos niveles de expresión: por un lado, un proceso de configuración de un saber cómo, que tiene que ver con un modus operandis subjetivo y corporal que posibilita la acción, y por otro, un proceso de estructuración de reglas y relaciones de poder que definen posiciones y condiciones de posibilidad de la acción discursiva.

En el primer caso, hablamos de un "marco expresivo" ligado a las dimensiones de la significación y la intencionalidad. Con este marco expresivo nos referimos a un saber práctico encarnado en el propio cuerpo y que posibilita las prácticas sociales. Constituye el trasfondo de disposiciones corporales, gestos y marcas estéticas que llevamos con nosotros mismos y que actúa como marco posibilitante de nuestra acción discursiva. Como señala Bourdieu: "El cuerpo cree en lo que juega: llora cuando mima la tristeza. No representa lo que juega, no memoriza el pasado, actúa el pasado, anulado así en tanto que tal, lo revive" (1991:124). De este modo, esta noción de trasfondo daría cuenta de la base corporal y performativa de la acción, proponiéndose al propio cuerpo como contexto de sentido para nuestras investigaciones.

En el segundo caso, nos referimos a un "marco normativo" asentado en las sedimentaciones históricas de la estructuración histórico-cultural. Este marco normativo corresponde a un contexto de regularidades formado por retazos de lenguaje y prácticas sociales, constituyendo un sistema de reglas de las cuales formamos parte, de modo que este trasfondo puede ser entendido a partir de las nociones Wittgeinteiniana de juegos de lenguaje y forma de vida. Como señala el propio Wittgenstein: "La expresión juego de lenguaje debe poner de relieve aquí que hablar hace parte de una actividad o forma de vida" (1988:23). De este modo, esta noción de trasfondo normativo daría cuenta de la base material, activa y social de la actividad simbólica, emergiendo el conjunto de prácticas, instituciones, relaciones y jerarquías, sedimentadas en la historia de una forma de vida, como contexto de sentido para nuestras investigaciones.

\section{b. De la construcción a la articulación}

La noción de "construcción" se fundamenta en la existencia de personajes bien definidos que ocupan claramente, y sin lugar a dudas, los ámbitos de sujeto constructor y objeto construido. Sin embargo, desde la perspectiva de la acción situada, la cuestión no está en dilucidar los actores de esos lugares cerrados propuestos por acción u omisión por la metáfora de la construcción, sino más bien, centrarse en las peculiares relaciones que tejen redes interminables entre diferentes tipos de actores en el marco de un trasfondo. Esto supone mirar a varios agentes en el proceso de investigación. Como señala Haraway: "Los actores no somos 'nosotros'. Si el mundo existe para nosotros como 'naturaleza', esto designa un tipo de relación, una proeza de muchos actores, no todos humanos, no todos orgánicos, no todos tecnológicos" (1999:23).

Desde esta perspectiva, resulta necesario explorar otras metáforas que nos provean de un lenguaje más coherente con esta perspectiva. La noción de "articulación" aparece en los planteamientos de varios autores que responden a tradiciones diferentes, -Latour, Haraway, Hall, y Laclau y Mouffe-, emergiendo como una provocadora propuesta para entender el proceso de constitución del mundo desde la coordinación, traducción, conflicto y mestizaje que supone que algo se "articule" con otra cosa.

En términos etimológicos, la palabra articulación puede referir tanto a la capacidad fonética de pronunciar palabras en forma clara y distinta, como al proceso de unión o ensamblaje de dos o más piezas en una organización más compleja. Para Laclau y Mouffe, la noción de articulación se define como "cualquier práctica que establezca relaciones entre elementos de manera que sus identidades sean modificadas como resultado de la práctica articulatoria" (1985:105). Y Haraway nos agrega que articular "es unir cosas, cosas espeluznantes, cosas 
arriesgadas, cosas contingentes" (1999:150).

A partir de esta idea de articulación, el conocer implica un proceso de reconstrucción siempre infinito e imposible, abierto a nuevas formas de relación entre los actores que se encuentran, enfrentan y mezclan en el proceso de investigación. Es decir, la relación entre investigador/investigado es una interacción de ida y vuelta, donde ninguno se constituye completamente al margen del otro y en donde ninguno sobrevive totalmente a la confrontación que produce el conocimiento. Solo si nos permitimos la re-definición del conocimiento como una práctica de articulación que constituye tanto al investigador como al investigado, podemos problematizar las implicancias políticas de la investigación como una práctica de subjetivación.

Desde esta perspectiva, ya no sólo nos interesa entender que hay otros actores que pueden contextualizar la acción de los seres humanos, sino que el interés estaría en iniciar un camino de reflexión teórica y metodológica para desarrollar estrategias de traducción que posibiliten comprender las capacidades "agenciales" del mundo de los artefactos, el espacio y la naturaleza. Ese entendimiento permitirá fijar la reflexión metodológica en un conjunto de procesos dinámicos de coordinación y conflicto entre distintas agencias que concurren en la experiencia de la investigación de la realidad social.

Sin embargo, antes de abordar explícitamente esta cuestión, resulta necesario analizar las implicancias de esta perspectiva en la teorización de un concepto clave para el desarrollo de la investigación social cualitativa como es la noción de discurso.

\section{Trasfondo, articulación y discurso}

Lo que nos proponemos argumentar en este apartado es que el discurso, en tanto categoría de estudio paradigmática de la investigación social cualitativa, constituye un dispositivo relacionado con las categorías de trasfondo y articulación, al ser el producto lingüístico o no-lingüístico de la articulación de los elementos semiótico- materiales dispersos en un trasfondo.

Desde esta perspectiva, tal como propone Foucault, el discurso es un artefacto distinto a la lengua, ya que nos remite al lecho de reglas anónimas que actúan como su propio trasfondo. El análisis de los discursos, entonces, nos remite al análisis histórico de las condiciones de existencia de los discursos, es decir, a la genealogía de aquel "todo" formado por el lenguaje y las acciones con las que éste está entretejido en un juego de lenguaje, y que constituye una de las manifestaciones más sistemáticas y estables de lo que aquí hemos llamado un "trasfondo normativo".

Es decir, los discursos constituyen un producto de la reorganización de elementos incompletos que se constituyen en una entidad estructural y con sentido, -es decir, en una identidad-, sólo en un momento particular de la propia práctica discursiva. Los elementos que convergen desde un trasfondo para constituir un discurso, no cuentan con una identidad definida a priori, ésta constituye el resultado de la "articulación" que se produce en la propia acción del discurso.

De este modo, cuando afirmamos que todo objeto se constituye en el discurso no tiene que ver con que todos los objetos del mundo sean "puro lenguaje", o que no exista nada en el mundo más allá del pensamiento; ambas conclusiones se derivan de una concepción errónea del discurso como una estructura de carácter mental reducible a una expresión puramente lingüística. Por el contrario, la noción de discurso que aquí proponemos, se refiere a una estructura "semiótico-material" situada en una formación o regularidad que incluye tanto los elementos lingüísticos como extra-lingüísticos de nuestra vida social.

Como plantea Wittgenstein, cuando en una situación social determinada, un sujeto le pide a su compañero de trabajo un ladrillo, y luego coloca dicho ladrillo en la pared que ambos están construyendo, podemos sostener sin ningún problema que estamos frente de dos acciones propiamente discursivas. Es obvio que la primera acción es lingüística y la segunda no, no obstante, ambas constituyen configuraciones significativas, y en ese sentido, ambas 
representan una práctica discursiva que incorpora las dimensiones materiales y simbólicas de la situación.

De ahí que "toda identidad u objeto discursivo se constituye en el contexto de una acción" (Laclau 2000:116), y todo significado lingüístico o extra-lingüístico se constituye en una actividad simbólica y material regulada por las manifestaciones de un trasfondo, porque toda práctica social constituye una totalidad significativa en donde dichas distinciones adquieren sentido. Como concluye Laclau: "Esto nos conduce nuevamente a la conclusión de que la distinción entre elementos lingüístico y no lingüísticos no se superpone con la distinción entre 'significativo' y 'no significativo', sino que la primera es una distinción secundaria que tiene lugar en el interior de las totalidades significativas" (2000:116).

De este modo, sería el mismo sistema de reglas que hace de un determinado fenómeno un objeto de investigación, el que hace del sujeto que trabaja con él un investigador, ambos elementos se constituyen en las reglas que actúan como trasfondo o totalidad significante de ambas identidades, las cuales forman un todo inseparable de las condiciones semiótico- materiales que les permiten existir. Es decir, podríamos decir que la identidad de los elementos que participan en una relación de investigación -como en cualquier otra relación social-, hacen parte del entramado que configura una forma de vida. Por ello es que el discurso, más que expresar la voluntad o intencionalidad de un sujeto investigado o investigador, produce versiones materiales y simbólicas del tipo de relación que se construye entre ambos.

\section{Investigación situada}

Como propuso Jesús Ibáñez, la investigación social es una operación de caza. En ella se realiza una doble operación, se dice algo sobre la realidad que actúa como presa, al mismo tiempo que se hace algo en ella. Pero en una operación de caza, la presa también puede hacer cosas, puede tener su propia agencia. Por ello, ampliando la metáfora original de lbáñez, podemos definir a la investigación cualitativa como una práctica articulatoria donde cazador y presa forman parte de una relación que los constituye mutuamente. El que tradicionalmente los investigadores hayan ocupado el lugar de cazador no significa que nuestras prácticas de investigación deban mantenerse de espaldas al mundo observado como presa silenciosa, por el contrario, si asumimos que la propia actividad de investigación es la que constituye estos lugares -cazador y presa- como ámbitos pre-existentes a la práctica de investigación, debemos asumir también que es esta misma práctica la que los puede reconstruir.

Por ello, el objetivo de este último apartado es discutir algunas consecuencias preliminares que tendría una perspectiva situada para la investigación social, analizando algunas prácticas específicas vinculadas a la implementación y análisis de dispositivos cualitativos de aproximación a la realidad social. A continuación se analizan cinco proposiciones que exploran algunos aspectos del debate sobre la investigación social cualitativa, con el objeto de abrir espacios o líneas de reflexión crítica sobre algunas de nuestras prácticas de investigación.

\section{a. La investigación cualitativa no implica ningún acto de sensibilidad superior}

Desde la perspectiva de la investigación situada tomamos distancia de la tradición que propone que cuando investigamos debemos hacer un acto de sensibilidad por medio del cual nos separamos de nuestros prejuicios para poder ponernos en el lugar del otro. Como plantea un texto clásico: "Para la perspectiva fenomenológica y por lo tanto para la investigación cualitativa es esencial experimentar la realidad tal como otros la experimentan. Los investigadores cualitativos se identifican con las personas que estudian para poder comprender cómo ven las cosas. (...) El investigador cualitativo suspende o aparta sus propias creencias, perspectivas y predisposiciones" (Taylor y Bodgan 1992:22).

Esta sensibilidad fenomenológica propuesta por Taylor y Bodgan para el quehacer de la investigación cualitativa nos parece una peligrosa ingenuidad. Kundera, desde la lucidez que le permite escribir desde la literatura, ya nos advertía sobre los peligros del uso de la sensibilidad: "la sensibilidad le es indispensable al hombre, pero se vuelve temible en cuanto se le considera un valor, un criterio de la verdad, la justificación del comportamiento" (1986:13). La posibilidad de que el discurso de la sensibilidad moralice la producción del conocimiento desde una cierta 
posición "estética" de aproximación al mundo, es tan polémica en sus consecuencias políticas y epistemológicas, que nos atrapa en la misma contradicción de la propuesta realista de que se puede encontrar un lugar privilegiado desde el cual ver el mundo con absoluta objetividad. Aquí sensibilidad y objetividad parecen las dos caras de una misma moneda.

En la investigación cualitativa, más que la sensibilidad del investigador, habría que problematizar hasta qué punto los entrevistadores-preceptores-observadores vienen a constituir un componente más del enjambre relacional que constituye la identidad de aquello que es investigado. Si el conocimiento es básicamente una actividad articulatoria: ¿cómo no podría serlo la práctica concreta de la investigación social? Por lo tanto, la alternativa no es la sensibilidad, no es el vacío existencial, o el abandono de la propia subjetividad, sino la elaboración particular e independiente de los procesos del propio investigador, el análisis de su lugar como parte de la red investigada: la alternativa es la auto-observación.

Una línea de trabajo interesante para abordar el desafío de la auto-observación la podemos encontrar en la autoetnografía, y en las múltiples experiencias de investigación en las cuales el "autor" describe un contexto cultural del cual es un participante activo observándose, rompiendo a través de un profundo involucramiento personal con el campo, la tradicional distancia entre sujeto investigador y objeto investigado (1). Lo que se propone no es el acercamiento sensible para "insertarnos" en un contexto determinado, sino la investigación de contextos en los cuales los investigadores también somos actores sociales que vivimos de una manera determinada aquello que es nuestra realidad. Del mismo modo, podemos extender la auto- observación al análisis y exploración critica de los aspectos naturalizados de nuestros contextos específicos de vida (2).

\section{b. En la investigación cualitativa habría que reconstruir el conjunto de disposiciones o estilos de acción del informante}

Desde la perspectiva de la acción situada, las prácticas sociales que pretendemos estudiar a través de dispositivos conversacionales están posicionadas en un trasfondo corporal e histórico, de manera que habría que dar más relevancia a los sistemas de observación y registro de las posturas corporales, los gestos y la proxémica de los sujetos, en tanto componentes no verbales del discurso que nos proponemos investigar. Hablamos de una mirada que correspondería a la investigación social etnográfica, aquella que por medio de la observación y la escucha biográfica nos permite investigar cuerpos situados en prácticas significantes, analizando relatos testimoniales que son reinscritos en lo que Cottet (2006) llama una "sintaxis escénica".

El registro etnográfico, entonces, surge como el acompañante fundamental de toda técnica conversacional/testimonial, implementando un segundo nivel de análisis, tal que, por ejemplo, los procesos no verbales del trabajo de grupo y la conversación individual puedan ser también objetos de análisis de nuestras investigaciones. El conocimiento que nos proponemos producir requiere de una elaboración cuya unidad sólo se puede restituir cuando lo podemos ver "aconteciendo escénicamente" (Cottet). Por ello, los registros textuales deben abrirle paso a los "registros visuales", siendo las fotografías y las grabaciones audiovisuales las que nos proveen más eficientemente de las claves para acceder a algunos elementos contextuales que actúan como trasfondo de la práctica social que investigamos (3).

Desde esta perspectiva, el desafío metodológico es desarrollar modificaciones parciales a los dispositivos puramente conversacionales, con tal de escapar de la tendencia de los métodos cualitativos por saturar la pura dimensión semántica del lenguaje, sea a través de técnicas centradas en su componente referencial o anafórico (Ibáñez). Para ello, debemos implementar dispositivos activos de investigación -podríamos decir incluso, dispositivos dramatúrgicos- que permitan poner en acción lo que hay de fuerza performativa en la situación. La idea es no sólo decir sino hacer con el lenguaje, sobrepasando los propios marcos a partir de los cuales se genera la reflexión: hablamos de investigar un actor actuando, analizar una perfomance en plena escenificación.

Ejemplos de lo anterior los pueden encontrar en el uso del "juego de roles" como acciones performativas en las cuales la investigación establece las condiciones para transformar los roles en tanto que generadores de normas 
sociales, o las experiencias de la "etnografía comprometida en la construcción de dispositivos de análisis de representaciones teatrales para indagar en los sentidos que construyen jóvenes estudiantes sobre las relaciones inter e intrageneracionales en el ámbito escolar (4).

\section{c. La investigación cualitativa debe explorar la red de sentido de la cual los sujetos somos parte}

Para la perspectiva de la acción situada, el resultado más directo y concreto del reemplazo de la metáfora de la construcción por la metáfora de la articulación, es que cuando investigamos el sentido de una práctica social, este no sólo radica en las narraciones que elaboran los individuos, sino que también proviene de los contextos y los objetos materiales que tienen incidencia en el desarrollo de dicha práctica social. Esto significa que debemos sobrepasar la tesis construccionista de situar las narraciones en un tiempo y un lugar, y dar paso al desafío metodológico de investigar el tiempo y el lugar como elementos narrativos con capacidad de significación.

Los realizadores de historias de vida lo saben desde hace mucho, cuando investigan los objetos con los cuales se articulan las narraciones de una biografía: un diario de vida, unas cartas antiguas, un juguete viejo, o un banco en el patio de la casa donde el entrevistado vivió su niñez, y que cuando vuelve a sentarse en él, pareciera que cambiaran radicalmente las posibilidades de su propia narración. La materialidad se articula con nuestra narración reconstruyendo el sentido de lo que investigamos, constituyendo por tanto no sólo contexto, sino texto que hace parte del sentido de la investigación. Siguiendo a Latour (2008), emerge la idea de red como alternativa para comprender estas interacciones semiótico-materiales, en tanto estructura relacional, múltiple y más o menos abierta, que se constituye a partir de la intersección o ensamblaje de unos puntos de paso o nodos. A partir de esta perspectiva, lo que somos, es un emergente de las relaciones en las cuales estamos situados, de modo que lo crucial para la investigación social no deben ser los nodos de la red en sí mismos, sino sus conexiones.

En la investigación social, más que representar una posición, nos articulamos con una red de conexiones semiótico-materiales que posibilitan que el fenómeno investigado se constituya de una manera determinada y no de otra. Las narraciones de los sujetos se estructuran a partir de esta red de conexiones que se experimenta en la vida cotidiana en las transformaciones del espacio, el tiempo y los artefactos. Por ello, investigar una biografía, por ejemplo, supone preguntarse también por la vida social de las cosas con las cuales el sujeto ha estado conectado o por las características de los espacios físicos donde ha vivido. Un caso lo podemos encontrar en estudios que analizan cómo se relacionan las transformaciones de los espacios físicos de los barrios con las narraciones biográficas de sus habitantes (5).

\section{d. La investigación cualitativa debe explorar más allá de los límites cercanos de la red de sentido de la cual somos parte}

Desde la perspectiva situada, nos articulamos con redes inmateriales de pura información a las cuales accedemos a través de objetos cotidianos como la computadora o el televisor. Los sujetos vivimos esta red de información como noticias, entretenimiento, instrucciones, orientaciones o publicidad. Probablemente esta red aparece con claridad para la investigación social si pensamos en los flujos interminables de información propios de la sociedad del conocimiento, especialmente si nos detenemos en los casos de Internet y las cadenas de medios de comunicación de masas.

James Clifford, por ejemplo, se plantea el problema de la investigación en Internet. Se pregunta por la posibilidad que tendría de ser reconocido como un investigador que hace su trabajo de campo, un sujeto que realiza un estudio sobre la cultura de los espías de computadoras (hackers) a través de varios meses de exploración en la red (Clifford 1999). Para nuestra perspectiva, el problema es claro, más allá de que se esté realizando una investigación descorporalizada, se está explorando un espacio intersticial, una suerte de interfase en la cual sujeto y tecnología establecen no una frontera, no un límite claro, sino que un espacio borroso en el cual se constituyen nuevas formas de subjetividad que resultan absolutamente relevantes de investigar. Parece relevante investigar los contactos, las amistades, los procesos de construcción de emociones que se establecen en la red, problematizando críticamente la subjetividad que allí se articula. 
Los medios de comunicación también merecen una consideración en esta perspectiva, porque también forman parte de esta red inmaterial de producción y reproducción del sentido. Emociones colectivas, miedos, euforias, son estados de ánimo articulados por sujetos que están conectados a una red de noticias que replica mundialmente imágenes y palabras a través de la televisión. Por ejemplo, cada cierto tiempo una palabra como "pandemia" junto a imágenes de gente en cuarentena cruza el globo a través de los noticiarios, y en cuestión de horas se genera temor y desazón en gente que está fuera de toda posibilidad de contacto físico con aquellos que padecen la enfermedad, demostrando la capacidad que tiene aquella red de información para materializarse en nosotros mismos (6).

La investigación social debe asumir que en estos flujos constantes de información se producen procesos de articulación. En muchas ocasiones, la reconstrucción de la escena en la cual deben reinscribirse los discursos, demanda leer la red inmaterial y tecnológica que le sirve de trasfondo. Los medios de comunicación, la red de redes de Internet y las múltiples imágenes que circulan allí, constituyen los materiales de una red cada vez más fluida, la cual se constituye en la superficie de construcción de una verdadera nueva ontología social (7).

\section{e. La investigación cualitativa debe construirse como un proceso de ida y vuelta entre observación, escritura y devolución}

Desde la perspectiva de la investigación situada debemos hacernos cargo de la incompletitud de la investigación social. No podemos pretender fijar una representación de una realidad sin devolverle la palabra a quienes se supone están representados en dicho conocimiento. La devolución constituye al mismo tiempo un acto de democratización y un acto de contextualización, en el cual el conocimiento hecho representación se somete a crítica, y a través de ella, reflexivamente vuelve a ponerse en acción.

Efectivamente, la investigación es un momento que cíclicamente termina a través de una nueva problematización. El movimiento Art Povera hace casi un siglo nos decía que a través de su arte no pretendían representar, sino que presentar. La investigación también debe abandonar su afán representacionista y asumir la misión de presentar una versión transitoria sobre el mundo que debe ser devuelta a sus protagonistas. Podríamos decir que la devolución y re-escritura del conocimiento nos remite a un acto de articulación, en el cual, al menos parcialmente, se le devuelve al discurso algunos elementos de su dimensión social, transformándose esta devolución en un momento en que se despliega transitoriamente el discurso como totalidad, para iniciar un nuevo proceso de crítica y desconstrucción.

La escritura de una investigación supone un acto de profanación de aquella imagen del conocimiento como un lugar incólume y libre del diálogo humano. Pero esta "des-divinización" del conocimiento no debe suponer que la investigación es un acto de moralidad intrínseca en la cual se entrega la palabra al postergado, que en virtud de su pura condición de postergación puede ver el mundo de manera correcta. Es decir, la investigación social debe terminar restituyéndole la palabra a los sujetos investigados para poder comprender, no porque éstos vean mejor el mundo, sino porque sin éstos la investigación no puede restituirle, ni siquiera transitoriamente su complejidad relacional a los fenómenos que pretende estudiar.

\section{Conclusiones}

Partimos este trabajo del supuesto que para repensar la investigación social cualitativa se requiere superar todas las formas de dualismo, tanto de aquellos que durante años han privilegiado la preeminencia de la estructura y/o la cognición por sobre cualquier forma de subjetividad, como también de aquellos que a través de su crítica al pensamiento polar, han vuelto a restablecer esta diferencia, ahora desde la supremacía de un sujeto que se impone sobre un mundo casi unilateralmente construido por él.

En este esfuerzo por abandonar los dualismos, incluso aquellos que se formulan desde la supremacía reivindicativa del sujeto, la investigación cualitativa emerge como una práctica por definición articulatoria, en la cual los diversos actores situados en unos contextos simbólicos y materiales que les sirven de trasfondo, participan en una 
verdadera experiencia de traducción. Efectivamente, actuar en el mundo, investigarlo, supone articularse con formas de agencia que se actualizan desde el trasfondo que comparten, de modo que los investigadores sólo pueden producir versiones parciales de la realidad, ya que tanto él como el fenómeno que estudia, son el resultado de los procesos materiales y simbólicos con los cuales se articulan.

Sin embargo, con la noción de articulación no pretendemos referirnos a la mera recombinación de elementos predefinidos y ya preexistentes, es decir, no planteamos la práctica de investigación como una relación entre una agencia humana que se enfrenta a un mundo compuesto por un conjunto de "objetos mudos", una suerte de mapa pasivo de rasgos externos frente a una interioridad activa y cognoscente del investigador, sino que se trataría de relaciones de articulación en las que todos los elementos re-construyen sus rasgos constitutivos en la propia relación.

La investigación social nos remite, entonces, a unas prácticas destinadas a la presentación, -no a la representación-, de una versión de lo que puede ser un determinado ámbito de la realidad. El presentar un conocimiento, supone dialogar con todos los que forman parte de la red, agentes humanos y no-humanos, sociales y naturales, simbólicos y materiales, no con el afán de privilegiar a uno de ellos como interlocutor exclusivo, sino para asumir en la práctica, las implicaciones epistemológicas de la metáfora de la articulación. Por ello es que la investigación social no es ventriloquia, es traducción. Es decir, una práctica de reconstrucción, a partir de la devolución de la palabra a sus propios actores, no como un modo de validar el acto de ventriloquia con aquellos a quienes supuestamente pretendemos representar, sino como un acto de democratización del propio proceso de producción y legitimación del conocimiento (8).

En síntesis, podemos concluir que la investigación social debe comprender y traducir, y para ello debe dialogar y reinscribir los testimonios, representados institucionalmente como resultados de una práctica científica de investigación, en una escena con cuerpos y lugares, tiempos y distancias. El acto de devolución de la palabra a los actores, permite el acto moral de la re-escritura y la contextualización, y éste a su vez hace inevitable el acto político de una nueva desconstrucción.

\section{Notas}

(1) Ver por ejemplo A. Scribano y A. De Sena (Construcción de Conocimiento en Latinoamérica: Algunas reflexiones desde la autoetnografía como estrategia de investigación).

(2) Ver por ejemplo D. M. Pane y T. Rocco (Critical Microetnografhy. The search for emancipatory methods).

(3) Ver por ejemplo H. Knoblauch et. al. (Visual Analysis. New developments in the interpretative analysis of video and photography).

(4) Ver por ejemplo H. Paulin et. al. (La representación teatral como dispositivo de investigación cualitativa para la indagación de sentidos sobre la experiencia escolar con jóvenes).

(5) Ver por ejemplo H. Berroeta y T. Vidal (Una propuesta multimétodo para un abordaje transaccional del espacio público en la escala de barrio).

(6) Ver por ejemplo J. Uotinen (Digital Television and the Machine That Goes "PING!": autoethnography as a method for cultural studies of technology).

(7) Al respecto ver F. García Selgas (Sobre la Fluidez Social: elementos para una cartografía).

(8) Al respecto ver S. Arensburg et. al. (From the subjectivity of the object to the subjectivation of research: practices of social research in Chile). 


\section{Bibliografía}

Bourdieu, P. 1991. El sentido práctico. Madrid: Taurus

Clifford, J. 1999. Itinerarios transculturales. Barcelona: Gedisa

Cottet, P. 2006. Diseños y estrategias de investigación social: El caso de la ISCUAL. En: M. Canales (editor) Metodologías de la investigación social: introducción a los oficios. Santiago: LOM, pp. 185-217.

Haraway, D. 1999. Las promesas de los monstruos: Una política regenerad ora para otros inapropiables/dos. Política y Sociedad 30: 121-163

Haraway, D. 1995. Ciencia, cyborgs y mujeres. La reinvención de la naturaleza. Madrid: Cátedra

Kundera, M. 1986. Jacques y su amo. Homenaje a Diderot. Barcelona: Tusquet

Laclau, E. 2000. Nuevas reflexiones de la revolución de nuestro tiempo. Buenos Aires: Nueva Visión

Laclau, E. y Mouffe, Ch. 1985. Hegemonía y estrategia socialista. Hacia una política democrática radical. Madrid: Siglo XXI

Latour, B. 2008. Reensamblar lo social. Una introducción a la teoría del actor-red. Buenos Aires: Manatial

Sandoval, J. 2004. Representación, discursividad y acción situada. Introducción crítica a la psicología social del conocimiento. Valparaíso: EDEVAL.

Searle, J. 1992. Intencionalidad (Un ensayo en la filosofía de la mente). Madrid: Tecnos

Taylor, S.J. y Bodgan, R. 1992. Introducción a los métodos cualitativos de investigación. México: Paidos

Wittgenstein, L. 1988. Investigaciones filosóficas. Barcelona: Cátedra

Recibido el 10 Ago 2012

Aceptado el 21 Ene 2013 